\title{
ANÁLISE DE METODOLOGIAS PARA AVALIAÇÃO DE EMPRESAS: ESTUDO APLICADO AO CASO DA AMÉRICA LATINA LOGÍSTICA
}

Bruno de Oliveira São Josél Wilson Lapa Santos Junior ${ }^{2}$ Ricardo Bordeaux-Rêgo ${ }^{3}$

Resumo: O presente artigo tem por objetivo comparar os métodos do Fluxo de Caixa descontado e do Múltiplo de Ebitda, utilizados na avaliação de ações. Para tanto, avaliou-se as ações da empresa América Latina Logística (ALL) negociadas na Bolsa de Valores de São Paulo. Foram utilizadas informações disponíveis ao público. Como resultado obteve-se que, apesar da maior consistência do método de avaliação pelo fluxo de caixa descontado em relação ao método de avaliação relativa, os valores convergiram e ficaram alinhados com os disponibilizados no mercado, o que pode ser explicado em parte pelo fato da empresa atuar em um setor mais intensivo em capital.

Palavras-chave: Análise de Investimentos, Custo Médio Ponderado de Capital, Fluxo de Caixa Descontado, Avaliação Relativa.

Abstract: This paper aims to quantitatively assess the value of an asset, in this particular case, the shares of America Latina Logística (ALL) traded on the São Paulo Stock Exchange. Through the use of publicly available information, the fair value of the company is calculated by the method of Discounted Cash Flow and EBITDA multiple. The results show that Discounted Cash Flow and multiple valuation bring similar results for the studied company. Maybe this consistency is credited to the intensive capital sector of ALLL.

Key-words: Investiment Research, Weigthed Average Cost of Capital, Discounted Cash Flow, Relative Valuation.

\section{INTRODUÇÃO}

A avaliação de empresas é um importante tema dentro da área financeira. A escolha do melhor método para essa avaliação tem sido um dos grandes desafios neste campo. Desde que o colapso da bolha imobiliária norte americana deflagrou a crise econômica de 2008, muito se tem questionado os métodos de avaliação envolvidos não só para empresas do ramo imobiliário.

A intenção de se avaliar as empresas é alcançar o seu preço justo em determinado momento, tendo em vista as suas potencialidades de fluxos de caixa, refletindo a influência das variáveis econômicas. Tal preço poderá servir como base para negociações de fusões e aquisições, e também para estratégias de investimentos em gestão de carteiras de ativos negociados em bolsas de valores.

Segundo Copeland (2002), o valor das ações de uma empresa no mercado de capitais é determinado com base nas expectativas que tem o mercado em relação ao desempenho futuro. Os retornos obtidos pelos acionistas dependeriam mais das mudanças quanto às expectativas do que do desempenho efetivo da empresa. Nesse sentido, o preço real da empresa só seria obtido havendo a interação de compradores e vendedores. $\mathrm{O}$ investidor racional nunca desejará pagar por um ativo mais do que seu valor percebido.

\footnotetext{
Graduado em Engenharia de Produção pela Universidade Federal Fluminense.

Graduado em Engenharia de Produção pela Universidade Federal Fluminense.

Prof. Orientador - Dept ${ }^{\circ}$ de Engenharia de Produção - UFF- Campus Niterói.
} 
Este artigo tem por objetivo apresentar e discutir dois modelos de valuation utilizados em instituições financeiras: os métodos de avaliação por fluxo de caixa descontado e de avaliação relativa por múltiplo de Ebitda (earnings before interests, depreciation and amortizations - lucro antes de juros, impostos depreciação e amortizaçōes LAJIDA) definido adiante. De modo a melhor ilustrar a aplicação dos métodos estudados, será feita a avaliação de uma empresa listada na Bolsa de Valores de São Paulo, a América Latina Logística (ALL), líder do setor de logística na América Latina para o modo ferroviário.

A eventual verificação de diferenças relevantes nos preços por ação encontrados pelos modelos indicará que a precificação de uma empresa não se dá a luz de uma ciência exata, e sim baseada em premissas que são observadas no mercado que refletem as incertezas vividas pelos analistas na aplicação dos métodos. Os resultados poderão dar subsídios para a avaliação de desempenho de equipes de avaliadores, à luz dos métodos por eles aplicados em seu trabalho.

\section{MODELOS DE AVALIAÇÃO DE EMPRESAS}

Segundo Damodaran (2007), uma questão fundamental enfrentada ao realizar avaliações é a que nível de detalhamento será decomposta a avaliação: por um lado, acrescentar mais detalhes permitiria aos analistas a oportunidade de usar mais informações para realizar melhores previsões sobre cada item. Por outro lado, isso tornaria necessário gerar mais inputs, elevando o potencial de ocorrência de erros sobre cada um.

Neste trabalho serão utilizadas duas abordagens propostas por Damodaran(2003): o método de avaliação pelo fluxo de caixa descontado (FCD), que relaciona o valor de um ativo ao valor presente de seus fluxos de caixa futuros; e a avaliação relativa, que determina o valor de um ativo com base na precificação de ativos comparáveis em relação a uma variável comum como ganhos, fluxos de caixa, valor contábil ou vendas.

\subsection{MODELO DE AVALIAÇÃO POR FLUXO DE CAIXA DESCONTADO}

Segundo Copeland (2002), o modelo FCD determina o valor acionário de uma empresa como sendo o de suas operações menos o endividamento e outras formas de passivo de prioridade superior à do capital ordinário. Pode ser aplicado a qualquer empresa, em qualquer momento, desde que seja possível prever seus fluxos de caixa futuros, tornando este método um dos mais fortes atuantes dentre as metodologias de avaliação. Damodaran (2003), por sua vez, afirma que na avaliação pelo modelo de fluxo de caixa descontado (FCD), o valor de um ativo é dado pelo valor presente dos fluxos de caixa previstos para este ativo, descontados a uma taxa que reflita o grau de risco desses fluxos de caixa.

A favor do método está a idéia de que os analistas tenham conhecimento dos negócios que estão avaliando e busquem os fundamentos que alavanquem o valor em oposição às percepções do mercado. Contudo, as avaliaçôes por FCD podem acabar superestimando o preço de um ativo se as percepçôes do mercado forem mal estimadas.

O método de fluxo de caixa descontado, parte da análise de quatro variáveis:

a. Fluxo de Caixa Líquido: capacidade de geração futura de caixa pelos ativos da empresa;

b. Período de Projeção: tempo em que o fluxo de caixa deverá ser projetado, durante o qual se conseguirá prever o comportamento das principais variáveis relacionadas aos ganhos e perdas operacionais. Depende da natureza do negócio e do grau de previsibilidade de suas variáveis mais relevantes;

c. Taxa de Desconto: é a taxa em que os fluxos de caixa serão descontados e trazidos a valor presente, refletindo da melhor maneira o custo de oportunidade e riscos dos fluxos de caixa;

d. Valor Residual: ao término do período de projeção, os fluxos de caixa não cobertos serão quantificados pelo valor residual (perpetuidade ou valor terminal). Essa será uma estimativa de valor presente que a empresa terá a partir do período de projeção. $\mathrm{O}$ valor será estimado baseado na expectativa de crescimento perpétuo que terá o fluxo de caixa livre para a empresa do último período de projeção, tornando este valor de suma importância dentro da avaliação.

\subsubsection{Fluxos de caixa líquidos}

Uma das primeiras necessidades para se avaliar uma empresa é o conjunto de demonstra- 
ções financeiras projetadas, a partir das quais serão obtidos os fluxos de caixa futuros. Os fluxos de caixa livres representam os lucros operacionais da empresa, após o pagamento de impostos, com o acréscimo de despesas que não geram saídas de caixa, como a depreciação, deduzidos os investimentos em bens de capital (capital expendure CA$P E X)$ e a variação de capital de giro líquido. $\mathrm{O}$ capital de giro líquido será a diferença entre o ativo circulante e o passivo circulante em determinado período.

Segundo Ross (2008), para a manutenção das atividades de uma empresa, esta terá que realizar investimentos em capital de giro líquido além dos investimentos em ativos a longo prazo. Esses valores considerar-se-ão saídas de caixa ao longo período de atividade da companhia.

\section{Equação 1 - Fluxo de Caixa Livre para a Empresa (FCLE)}

\section{FCLE = L. Operac. (1-Alíquota I.R.) - (Gastos de capital - Deprec.) - Alteração em Capital de Giro não Monetário}

Silva (2006), por sua vez, calcula o fluxo de caixa para os acionistas a partir dos fluxos de caixa livres sendo subtraídos os juros líquidos e a amortização de empréstimos. O valor da empresa para o acionista será obtido ao descontarem-se os fluxos de caixa para os acionistas pela taxa exigida pelos investidores sobre o capital próprio. Já o valor da empresa poderá ser obtido a partir dos fluxos de caixa livres para a empresa e de seu valor terminal, pressupondo que os fluxos de caixa crescerão a uma taxa uniforme sustentada por um tempo indeterminado, como mostrado pela equação 2, a seguir.

\section{Equação 2 - Valor da Empresa}

$$
\begin{gathered}
\text { Valor da empresa }= \\
\sum_{t=1}^{n} \frac{F C t}{(1+r)^{t}}+\frac{\text { Valor Terminal }_{\mathrm{n}}}{(1+r)^{n}}
\end{gathered}
$$

Onde:

$F C_{t}$ : fluxo de caixa no tempo t, $r$ : taxa de desconto, $n$ : período de projeção.

Para o caso do fluxo de caixa ao acionista, a taxa de desconto será o custo de capital próprio. Já para o caso do fluxo de caixa livre, a taxa será obtida pelo custo médio ponderado de capital (Weighted Average Cost of Capital - WACC).

\subsubsection{Taxa de desconto}

A taxa de desconto utilizada para determinar o valor da empresa é geralmente calculada pelo custo médio ponderado de capital (WACC). Segundo Ross (2008), o WACC é o retorno total que a empresa precisa gerar sobre seus ativos para manter o valor de suas ações, sendo também o retorno exigido sobre qualquer investimento que tenha o mesmo risco de suas operações atuais. Tem sido largamente utilizado por muitas empresas para avaliar o desempenho financeiro. De fato, Graham e Harvey (2001) em pesquisa realizada com 392 executivos financeiros das 500 maiores empresas americanas, encontram que cerca de 45 por cento dos entrevistados utilizam o WACC de forma a definir a estrutura de capital que o minimize, sendo 10 por cento mais rigidamente e 35 por cento de forma mais flexível.

Copeland (2002) afirma que o WACC deve satisfazer algumas características:

- Compreender uma média ponderada dos custos de todas as fontes de capital - terceiros ou próprio - uma vez que o fluxo de caixa livre representa o caixa disponível para todos os fornecedores de recursos;

- Ser computada após os impostos devidos, uma vez que o fluxo de caixa livre é declarado após os impostos;

- Utilizar taxas nominais de retorno construídas a partir das taxas reais e da inflação prevista, sendo que o fluxo de caixa livre previsto é expresso em termos nominais;

- Ajustar para o risco sistêmico suportado por cada fornecedor de capital, uma vez que cada um deles espera um retorno que remunere o risco assumido;

- Empregar as ponderaçóes de valor do mercado para cada elemento de financiamento porque o valor de mercado reflete os reais efeitos econômicos de cada tipo de financiamento;

- Se sujeitar às mudanças ocorridas durante o período de previsão do fluxo de caixa.

O WACC pode ser calculado segundo a equação 3: 
Equação 3 - Custo Médio Ponderado de Capital (WACC)

$W A C C=K_{E} *(E /(D+E))+K_{D} *(D /(D+E)) *(1-T)$

Onde:

- $E /(D+E)$ é o peso de capital próprio $E$ (Equity) na empresa;

- $(D /(D+E)$ é o peso de capital de terceiros $D(D e b t)$ na empresa;

- $K_{E}$ é o custo de capital próprio;

- $K_{D}$ é o custo de capital de terceiros;

- T é a alíquota tributária sendo uma combinação de IR e Contribuição Social sobre o Lucro Líquido.

O custo de capital de terceiros, segundo Damodaran (2007), se baseia na taxa em que a empresa pode captar no presente e dependendo $\mathrm{da}$ avaliação (rating) de riscos. Além disso, o benefício fiscal provindo das despesas com juros dedutíveis de imposto reduzirá o custo de crédito após os impostos. Copeland (2002) exclui o passivo livre de juros, como contas a pagar, do cálculo do WACC para evitar incoerências e simplificar a avaliação. Esse passivo tem custo, mas o seu custo está devidamente implícito no valor pago pelos bens que geraram a dívida.

\subsubsection{Custo do Capital Próprio - Capital Asset Pricing Model-CAPM}

O modelo mais conhecido e largamente utilizado em finanças para o cálculo do custo de capital próprio é o CAPM - Capital Asset Price Model. De fato, o trabalho de Graham e Harvey (2001) aponta que 73,5 por cento dos executivos pesquisados utilizam o CAPM como método de estimação do custo de capital próprio.

Segundo Ross (2008), o CAPM mostra que o retorno esperado de determinado ativo depende de três fundamentos:

1. Valor puro do dinheiro no tempo, este medido pela taxa livre de risco, que mostra a recompensa exigida pela simples espera pela devolução do dinheiro, sem, contudo, assumir qualquer tipo de risco.

2. Recompensa por assumir um risco sistemático, sendo medido pelo prêmio por risco de mercado que corresponde à recompensa que o mercado oferece para se assumir um nível médio de risco sistemático.
3. Por fim, o nível de risco sistemático, este medido pelo Beta $(\beta)$, que é o nível de risco sistemático presente em determinado ativo.

Equação 4 - Custo de Capital Próprio - CAPM

$$
K_{E}=R_{f}+\beta *\left(R_{m}-R_{f}\right)
$$

Onde:

- $K_{E}$ é o retorno esperado pelo ativo;

- $R_{f}$ é o retorno de um ativo livre de ris$\mathrm{CO}$;

- $\beta$ é o risco sistemático ou não-diversificável de um ativo diante do mercado;

- $R_{m}$ é o retorno esperado de uma carteira de mercado;

- $\left(R_{m}-R_{f}\right)$ é o prêmio pelo risco da carteira de mercado.

O custo de capital aumenta linearmente como função do risco não-diversificável medido, beta. O beta de uma carteira de mercado será igual a 1,0 (hum), e irá variar de acordo com o maior risco e retorno que terá o ativo perante o mercado.

Uma interpretação para a equação 4, pode ser: se o investidor quiser realizar com recursos próprios um projeto com risco de mercado ou sistemático $\beta$, deverá exigir, no mínimo, a remuneração que obteria "sem risco" em títulos do governo, acrescida do justo prêmio pelo risco incorrido.

\subsubsection{Valor Terminal}

Segundo Damodaran (2007), o valor terminal pode ser calculado de três formas:

1. assumir e estimar a liquidação dos ativos da empresa no ano terminal;

2. avaliar a empresa pela sua continuidade operacional a partir de uma data, aplicando um múltiplo a receitas, lucros ou valor contábil;

3. a última, aplicada neste trabalho, pressupóe que os fluxos de caixa da empresa terão crescimento perpétuo a uma taxa constante a partir de uma data.

Considerando que o custo de capital e a taxa de crescimento são sustentáveis para sempre, o valor residual pode ser calculado pela equação 5:

\section{Equação 5 - Valor Terminal}

Valor Terminal ${ }_{\mathrm{n}}=\frac{F C E_{n} *(1+g)}{W A C C-g}$ 
Onde:

- $F C E_{n}$ é o fluxo de caixa no último ano de projeção;

- $g$ é a taxa de crescimento perpétuo;

- WACC custo médio ponderado de capital, a taxa de desconto.

Damodaran (2007) pondera que a taxa de crescimento perpétuo não pode exceder à taxa de crescimento da economia onde a empresa atua, somente podendo ser inferior.

\subsection{MODELO DE AVALIAÇÃO RELATIVA}

O modelo de avaliação relativa, também conhecido por avaliação por múltiplos, procura encontrar o valor de um ativo pela comparação com os valores de outros ativos semelhantes. Segundo Damodaran (2007), encontrar ativos semelhantes é um desafio, porque não existem dois ativos que sejam exatamente iguais: empresas do mesmo segmento podem diferir em risco, potencial de crescimento e fluxos de caixa, tornando o processo de avaliação suscetível a erros. Para a ALL, como no Brasil não existem empresas de capital aberto na BOVESPA que possam servir como comparação, tornou-se necessária a pesquisa em outros mercados próximos.

Para uma melhor comparação entre empresas similares, os principais múltiplos são resumidos a seguir, a partir de uma listagem mais ampla de Damodaran (2003):

a. Múltiplo de Lucro - Preço/Lucro: este múltiplo é um dos mais utilizados pelo mercado para comparar empresas similares. $\mathrm{O}$ trabalho de Graham e Harvey (2001) aponta que 38 por cento dos entrevistados utilizam a relação Preço/Lucro (Price/Earnings- P/E) para a tomada de decisão de investimento. Este indicador mostra o quanto os investidores estão dispostos a pagar por unidade de lucro da empresa. Esta razão é de fácil obtenção no pelos balanços trimestrais que as empresas são obrigadas a divulgar.

b. Múltiplos de Valor da Empresa: Valor da Empresa/EBIT e Valor da Empresa/EBITDA. Na incorporação de um negócio, pode-se examinar o valor da empresa como um múltiplo de lucro operacional (EBIT) ou com os lucros antes de juros, impostos, depreciação e amortização $(E B I T D A)$.

A equação 6 apresenta a fórmula do valor da empresa pelo múltiplo de EBITDA.

\section{Equação 6 - Valor do Equity pelo Múltiplo de EBITDA}

$E=\left(E B I T D A^{*} M U^{\prime} L T I P L O\right)-D I ́ V I D A L I ́ Q U I D A$

Onde:

- $E=$ Market Value: valor de mercado das ações

- $E B I T D A=$ Lucro antes de juros, impostos depreciação e amortizações;

c. Múltiplos de Valor Patrimonial: Preço/Valor Patrimonial e Preço/Valor Patrimonial dos Ativos. Segundo Damodaran (2003), a estimativa contábil do valor da empresa é influenciada pelo preço original pago pelos ativos e por todos os ajustes contábeis feitos. Muitos investidores analisam a relação entre o valor pago por uma ação com o valor contábil da ação, sendo esta a razão: Preço/Valor Patrimonial.

d. Múltiplos de Valor de Reposição:

Valor da Empresa/Custo de Reposição dos seus Ativos (também chamado de q de Tobin). Desenvolvido por Tobin e Brainard (1968) e Tobin (1969), tem sido bastante aplicado em pesquisas em finanças.

e. Múltiplos de Receita:

Preço/Vendas e

Valor da Empresa /Vendas.

Os múltiplos de lucros e valor patrimonial são influenciados por regras e princípios de contabilidade, sendo uma alternativa a esse problema o cálculo dos múltiplos de receita pela razão do valor do negócio pelas receitas geradas (Preço/Vendas). Essa razão pode variar bastante conforme o segmento de atuação da empresa devido às margens de lucro. A vantagem em utilizar os múltiplos de receitas é a facilidade de aplicação em empresas de mercados diferentes, mesmo que os sistemas contábeis sejam diferentes. A desvantagem mais grave é a atribuição de valor a empresas que apresentem prejuízos freqüentes, apenas com base em suas vendas.

Segundo Damodaran (2003), para a utilização dos múltiplos deve-se:

1. Assegurar que o múltiplo esteja definido de forma consistente e medido com uniformidade entre as empresas comparáveis;

2. Conhecer a distribuição dos valores não só entre empresas do segmento em análise, mas em todas as do mercado; 
3. Saber não somente quais os fundamentos que determinam os múltiplos, mas também que variaçôes teriam estes com as modificações nos fundamentos;

4. Definir as melhores empresas comparáveis e verificar as possíveis diferenças que possam existir.

A seguir, apresenta-se a avaliação da ALL.

\section{ESTUDO DE CASO: AMÉRICA LATINA LOGÍSTICA}

\subsection{A EMPRESA}

A empresa estudada, América Latina Logística é a única empresa de capital aberto que atua no setor de logística no modo ferroviário. Foi fundada em março de 1997 e, de início, começou com a Ferrovia Sul Atlântico (FSA), na região sul do país. Em dezembro de 1998 iniciou as suas operações na região sul do estado de São
Paulo. Em agosto de 1999, conseguiu as concessões das ferrovias argentinas, Mesopotâmica e Central. Em julho de 2001 adquiriu os ativos da Delara. Mais tarde, em março de 2004, realizou a sua oferta primária de ações na Bovespa. A empresa pertence ao nível de governança corporativa do nível II, explicado adiante. Em maio de 2006 conseguiu mais concessões no Brasil com aquisição da Brasil Ferrovias e da Novoeste Brasil. A empresa está correlacionada diretamente com as flutuações das commodities, produtos por ela transportados. Como exemplos, pode-se citar minérios, aço, grãos, entre outros. A principal receita da empresa vem de suas operações no Brasil, mas também é influenciada pela sua subsidiária da Argentina.

A composição do capital da América Latina Logística é apresentada na tabela 1 . Seu grupo controlador é o fundo de investimentos Emerging Markets Capital Investments, LLC com sede nos Estados Unidos.

\section{Tabela 1 - Composição do Capital Votante}

\begin{tabular}{|l|r|r|}
\hline \multicolumn{1}{|c|}{ Grupo Controlador } & Ações Ordinárias & \multicolumn{1}{c|}{ \% Total } \\
\hline Emerging Markets Capital Investments, LLC & 92.205 .444 & $9,32 \%$ \\
\hline BNDES Participações S.A. - BNDESPAR & 86.544 .561 & $8,75 \%$ \\
\hline Hana Investments, LLC & 81.852 .224 & $8,28 \%$ \\
\hline Judori Administração, Empreendimentos e Participações S.A. & 81.925 .100 & $8,28 \%$ \\
\hline Wilson Ferro de Lara & 74.636 .697 & $7,55 \%$ \\
\hline Caixa de Previdência dos Funcionários do Banco do Brasil - PREVI & 31.109 .456 & $3,15 \%$ \\
\hline Fundação dos Economiários Federais - FUNCEF & 29.812 .062 & $3,01 \%$ \\
\hline Riccardo Arduini & 26.788 .900 & $2,71 \%$ \\
\hline Spoornet do Brasil Ltda. & 5.357 .200 & $0,54 \%$ \\
\hline Latin America Growth Capital & 3.181 .150 & $0,32 \%$ \\
\hline Advance Administração e Participações Ltda. & 1.056 .650 & $0,11 \%$ \\
\hline Gruçaí Participações S.A. & 478.756 & $0,05 \%$ \\
\hline TOTAL & 514.948 .200 & $52,08 \%$ \\
\hline
\end{tabular}

Fonte: America Latina Logística, agosto de 2009.

A ALL atua nas regióes centro oeste, sul e sudeste do Brasil assim como parte da Argentina, Chile e Paraguai, possuindo mais de 21 mil quilômetros de concessão ferroviária e ligação direta com os Portos de Santos, Paranaguá, São Francisco do Sul e Rio Grande, no Brasil, além de Rosário, San Nicolas e del Guazú, na Argentina. Seu principal serviço oferecido é a logística de commodities agrícolas como milho, trigo, soja, farelo, óleo vegetal e açúcar. No segmento de óleo vegetal em parceria com os maiores players do setor como Bunge, Cargill, Coinbra, Agrenco e Imcop, faz o escoamento para os portos de Paranaguá, São Francisco, Santos e Rio Grande. 
A ALL recebeu, através de licitação, a concessão para prestar o serviço público de transporte ferroviário de cargas nas malhas Sul (PR, SC, RS), Oeste (MS) e Paulista (SP) da extinta Rede Ferroviária Federal (RFFSA), pelo período de 30 anos. Para estes trechos a ALL firmou contrato de arrendamento dos bens necessários a prestação do serviço concedido (chamados de Bens Operacionais), segundo informaçôes da Agência Nacional de Transportes Terrestres, ANTT.

As empresas controladas da América Latina Logística têm prazo de concessão de trinta anos e poderão ser renovadas até o limite máximo total de trinta anos, a exclusivo critério da ANTT. $\mathrm{Na}$ Argentina, o prazo das concessões é de trinta anos, podendo ser prorrogadas por mais dez anos, em que pese a ALL ter iniciado suas operações na Argentina em 1999.

A tabela 2 e a figura 1 apresentam, respectivamente, as fatias de mercado porto e a composição da receita da ALL por segmento.

Tabela 2 - Escoamento Agrícola

\begin{tabular}{|l|r|r|}
\hline Market share por porto & $3^{\circ}$ TRI/09 & $3^{\circ}$ TRI/08 \\
\hline São Francisco do Sul ( SC) & $91 \%$ & $94 \%$ \\
\hline Paranaguá (PR) & $90 \%$ & $88 \%$ \\
\hline Rio Grande (RS) & $85 \%$ & $82 \%$ \\
\hline Santos (SP) & $56 \%$ & $61 \%$ \\
\hline
\end{tabular}

Fonte: América Latina Logística

\section{Composição da Receita \%}

Commodities Agrícolas $\square$ Produtos Industriais
$\square$ Argentina
Serviços Rodoviários

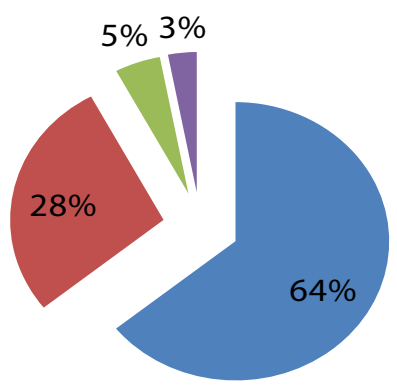

Fonte: América Latina Logística.

Figura 1 - Composição da Receita por Tipo de Produto Transportado

\subsection{PRINCIPAIS CONCORRENTES}

O mercado de logística no país está concentrado em duas empresas: a América Latina Logística e a MRS logística S.A. Um concorrente direto é o sistema rodoviário.

Embora essas empresas não atuem na mesma malha ferroviária, é interessante para a avaliação da ALL utilizar uma comparação com uma empresa semelhante, com características similares, em um mesmo mercado. A MRS Logística S.A. é uma concessionária que controla, opera e monitora a Malha Sudeste da Rede Ferroviária Federal, que concentra aproximadamente 65\% do Produto Interno Bruto do Brasil e estão instalados os maiores complexos industriais do país. Pela malha da MRS é possível alcançar os Portos de Sepetiba e de Santos.

\subsection{O MERCADO FERROVIÁRIO NO BRASIL E NA ARGENTINA E ESTADOS UNIDOS}

Segundo a ANTT, em 2007 a malha ferroviária brasileira consistia de um total de 29.817 quilômetros de linhas, predominantemente concentradas nas regiōes Sul, Sudeste, e Centro-Oeste do país. Em 2007, a área servida pela malha ferroviária brasileira respondeu por aproximadamente $74 \%$ do PIB brasileiro. A densidade das vias ferroviárias no Brasil é aproximadamente 5,8 vezes menor que nos Estados Unidos e muitos corredores já operam em sua capacidade máxima.

O sistema ferroviário brasileiro concedido à exploração da iniciativa privada possui 28.840 quilômetros, segundo a ANTT. O sistema ferroviário brasileiro era, em 2007, sétimo maior do mundo e o maior da América Latina em termos de carga transportada, atingindo 255,3 bilhōes de TKU (tonelada por quilômetro útil). $\mathrm{O}$ transporte de passageiros é praticamente limitado ao transporte urbano, com aproximadamente 1,52 bilhão de passageiros transportados por ano, incluindo o sistema metroviário.

A malha ferroviária argentina possuía, 32.170 quilômetros, concentrados nas províncias de Buenos Aires, Córdoba, Santa Fé e Entre Rios. Apesar da desestatização, as operações ferroviárias argentinas não conseguiram se recuperar a sua participação de mercado que continua concentrado principalmente no transporte rodoviário. 
Como no Brasil, os serviços de transporte rodoviário na Argentina são prestados livremente, sendo que o preço dos combustíveis é o principal fator determinante para a fixação das tarifas para os fretes.

O transporte ferroviário nos Estados Unidos tem uma forte presença na economia do país. Neste trabalho serão utilizados dados de empresas norte americanas para realizar a avaliação por múltiplos. A Union Pacific é uma empresa ferroviária dedicada ao transporte de mercadorias. É uma das maiores empresas ferroviárias da América do Norte, e a sua rede é a maior do país, com $52.838 \mathrm{~km}$, em um total de vinte e dois estados. A sua concorrente imediata, a Burlington Northern Santa Fe Corporation tem operações em vinte e oito estados americanos e em três províncias canadenses e opera principalmente no transporte de mercadorias, especialmente carvão e cereais, mas também opera alguns serviços de passageiros urbanos. As vias férreas desta empresa totalizam cerca de 51.000 quilômetros, segundo dados do Instituto de Logística e Supply Chain (ILOS).

$\mathrm{O}$ aporte para o investimento inicial é superior em equipamentos e infra-estrutura; em um primeiro momento é o tempo para a construção de ferrovias e estações que é superior ao da construção de estradas e centros de distribuição rodoviários. Apesar disso, o seu custo variável é bem inferior ao rodoviário. A Tabela 3 apresenta o comparativo dos preços médios por Mil TKU cobrados por diferentes modos no Brasil e nos Estados Unidos.

Tabela 3 - Comparativo preços médios por modos: Brasil versus EUA

\begin{tabular}{|l|c|c|c|c|}
\hline & \multicolumn{2}{|c|}{ Brasil } & \multicolumn{2}{c|}{ Estados Unidos } \\
\hline Modal & \% de Carga & US\$/ Mil TKU & \% de Carga & US\$/ Mil TKU \\
\hline Aéreo & $0,1 \%$ & 721 & $6,0 \%$ & 832 \\
\hline Dutoviário & $4,7 \%$ & 31 & $20,1 \%$ & 5 \\
\hline Aquaviário & $13,9 \%$ & 29 & $11,5 \%$ & 2.008 \\
\hline Rodoviário & $55,8 \%$ & 118 & $29,6 \%$ & 283 \\
\hline Ferroviário & $25,4 \%$ & 18 & $38,5 \%$ & 18 \\
\hline
\end{tabular}

Fonte: Panorama “Custos Logísticos no Brasil - 2008” - COPPEAD

\subsection{O SISTEMA RODOVIÁRIO NO BRASIL}

O transporte rodoviário é hoje a principal modalidade para a movimentação de cargas no Brasil. Os serviços são geralmente fornecidos por donos de caminhões independentes, sem capacidade de centralização para grandes volumes de carga. A receita da indústria rodoviária advém de tarifas baseadas na distância percorrida ou no volume das mercadorias transportadas. Estas tarifas respondem por entre $0,8 \%$ e $2,0 \%$ do preço final dos produtos industrializados e entre $15 \%$ e $20 \%$ do preço final dos produtos da agricultura, segundo a ANTT. Os preços das tarifas são correlacionados aos preços dos combustíveis. A tributação representa cerca de $30 \%$ do faturamento. Segundo Fleury (2009), os custos resultantes de manutenção e conservação precárias das estradas são sentidos diretamente no aumento de consumo de combustível e na maior incidência de acidentes em comparação com padrôes americanos.

Com exceção de determinadas regras aplicáveis ao transporte de cargas perigosas, os serviços de transporte rodoviário não estão sujeitos a regulamentação específica, prevalecendo as regras de livre mercado. Não há empresas de capital aberto no modo rodoviário e, segundo a ANTT, noventa e cinco por cento das empresas deste setor são consideradas micro ou pequenas.

\subsection{FATORES DE RISCO RELACIONADOS À ALL}

Entre os principais riscos relacionados à ALL, estão:

- concessões ferroviárias brasileiras e argentinas estão sujeitas à extinção antecipada nas circunstâncias determinadas por lei, 
pelo poder concedente, ou pelo descumprimento de termos dos contratos;

- necessidade de manutenção de um grupo de controle com mais de $50 \%$ das ações votantes (ONs) bloqueadas para negociação;

- concentração de receitas em poucos clientes;

- custos de combustível;

- controle das tarifas de serviços de transporte ferroviário: no mercado brasileiro são corrigidas anualmente de acordo com a variação do IGP-DI. No mercado argentino as tarifas são negociadas e cobradas em bases de mercado, calculadas em pesos na cotação de um para um com o dólar;

- exposição a taxas de juros flutuantes em grande parte do financiamento;

- riscos e perigos ambientais, incluindo o transporte, manuseio e uso de derivados de petróleo e produtos inflamáveis, não cobertos por seguro;

- risco sistemático, também denominado de mercado: mudanças cambiais, inflação e taxas de Juros, instabilidade social, desabastecimento de energia, liquidez de capital doméstico e política fiscal.
A ALL também está sujeita a fatores de risco similares em seus negócios e operações na Argentina.

\subsection{AVALIAÇÃO DA AMÉRICA LATINA LOGÍSTICA- METODOLOGIA E RESULTADOS}

\subsubsection{O fluxo de caixa descontado}

O período de investimento considerado na projeção foi de 2009 a 2014, se tornando perpétuo a partir deste. No setor estudado, intensivo em capital, as barreiras de entrada são extremamente altas devido. Na região de atuação da ALL não foi contemplada a entrada de nenhum competidor ferroviário devido ao alto custo envolvido. Dessa forma, o volume estará atrelado ao crescimento da economia através do referencial Produto Interno Bruto (PIB). Segundo o relatório FOCUS do Banco Central (BACEN) divulgado em 23 de novembro de 2009, a estimativa para o crescimento da economia foi de 0,21\% ao ano para 2009 e para $5,00 \%$ para 2010 . Para os anos de 2011 a 2014 foi utilizada a média de $4,00 \%$ ao ano de taxa constante de aumento, em cada segmento que a empresa esteja inserida.

A Receita Bruta considerou as vendas feitas sem que seja descontado nenhum imposto ou outro tipo de encargo. Para as projeçóes foram utilizados os anos de 2006 e 2007.

Tabela 4 - Receita Bruta

\begin{tabular}{|c|c|c|c|c|c|c|c|c|c|}
\hline & 2014 & 2013 & 2012 & 2011 & 2010 & 2009 & 2008 & 2007 & 2006 \\
\hline $\begin{array}{c}\text { Receita Bruta } \\
\text { (milhōes de R\$) }\end{array}$ & $\mathbf{3 . 7 0 2 , 1 4}$ & $\mathbf{3 . 5 5 7 , 6 8}$ & $\mathbf{3 . 4 1 8 , 8 6}$ & $\mathbf{3 . 2 8 5 , 4 6}$ & $\mathbf{3 . 1 4 5 , 6 9}$ & $\mathbf{2 . 9 9 7 , 4 0}$ & $\mathbf{2 . 8 2 8 , 3 0}$ & $\mathbf{2 . 3 8 1 , 4 1}$ & $\mathbf{2 . 2 9 1 , 4 8}$ \\
\hline
\end{tabular}

Para a avaliação da ALL foram simulados investimentos na empresa de aproximadamente $R \$$ 4,5 bilhões de reais, para o período estimado da avaliação de cinco anos. Segundo dados históricos da empresa, de seus últimos oito balanços trimestrais, para investimentos em locomotivas, vagóes e outros equipamentos, existe a necessidade de realizar um empréstimo para $80 \%$ deste valor. Foi utilizado o sistema SAC onde a amortização do financiamento é constante. Não foram informados valores de financiamento para o período de 2006 até 2009.
A Receita Líquida de uma empresa é a diferença de sua receita bruta e os impostos cobrados diretamente, tais como o ISS, ICMS e IPI. No caso da ALL foi calculada a partir de valores históricos entre a razão da receita líquida sobre receita bruta. Nesse caso foi utilizada a média móvel de quatro períodos para o cálculo do quinto período.

O custo dos serviços prestados (CSP) incluiu os recursos consumidos pela empresa para a realização do serviço de transportes ofertado pela ALL. Foram projetados os seguintes itens: combustível, agregado e terceiros, despesas com mão 
de obra, manutenção, concessão e arrendamento entre outras.

A projeção do item combustível foi aberta por consumo (litros/1000 TKB) e com valores históricos para o modal ferroviário de 5,6 litros/ $1000 \mathrm{TKB}$, mantidos a valores constantes, de acordo com relatórios da ALL sobre consumo ferroviário, assim como o ferroviário. Para o volume consumido projetado no período foi utilizada a mesma proporção da variação dos produtos agrícolas, industriais e segmento na ALL Argentina.

Para o sistema rodoviário o consumo foi calculado em 0,4 litros de combustível para cada quilômetro percorrido. As projeçōes para o aumento do combustível foram realizadas através da variação do preço do óleo diesel nos últimos quatro anos que foi de $1,86 \%$ ao trimestre, de acordo com a Agência Nacional de Petróleo (ANP).

$\mathrm{O}$ valor do salário de funcionários próprios e terceirizados foi atrelado ao índice oficial do governo, o IPCA. Segundo o relatório FOCUS de 23 de novembro de 2009 os valores de crescimento da economia para o último trimestre de 2009 é de $0,2 \%$ e para 2010 o valor é de $5,0 \%$ ao ano. Para os demais anos da projeção foi utilizado o valor de constante de $4,0 \%$ ao ano. Nessa projeção a mão de obra foi considerada custo fixo, pois não irá variar de acordo com a variação da demanda. Os custos de manutenção, arrendamento, concessão e outros, foram projetados em função da margem histórica.

O lucro operacional bruto é o resultado diferença da receita líquida e o custo do produto vendido. As despesas operacionais são gastos que a empresa necessita para se manter, mas que não estão necessariamente atreladas a algum produto. Para a ALL foram projetadas em função da margem da receita líquida, utilizando sua margem histórica. Foram utilizadas as despesas administrativas, despesas operacionais, além do resultado em equivalência patrimonial. Um indicador utilizado pela avaliação por múltiplos, o EBITDA(Earnings before taxs interests depreciation and amortization) - Lucro Operacional antes de Juros e Impostos e Depreciação LAJIDA apresentado na Tabela 5.

\section{Tabela 5 - LAJIDA (EBITDA)}

\begin{tabular}{|l|r|r|r|r|r|r|}
\hline \multicolumn{1}{|c|}{ Valores em R\$ milhões } & \multicolumn{1}{c|}{ 2014E } & \multicolumn{1}{c|}{$2013 \mathrm{E}$} & \multicolumn{1}{c|}{$2012 \mathrm{E}$} & \multicolumn{1}{c|}{$2011 \mathrm{E}$} & \multicolumn{1}{c|}{ 2010E } & \multicolumn{1}{c|}{ 2009E } \\
\hline Receita Líquida & $3.265,44$ & $3.138,03$ & $3.015,48$ & $2.895,74$ & $2.777,11$ & $2.641,43$ \\
\hline Custo do Produto Vendido & $(1.652,11)$ & $(1.534,93)$ & $(1.427,63)$ & $(1.329,23)$ & $(1.236,24)$ & $(1.145,21)$ \\
\hline Lucro Operacional Bruto & $1.936,96$ & $2.081,55$ & $2.119,94$ & $2.151,72$ & $2.194,45$ & $1.496,23$ \\
\hline Despesas operacionais & $(124,40)$ & $(119,54)$ & $(114,88)$ & $(110,40)$ & $(105,70)$ & $(100,72)$ \\
\hline $\begin{array}{l}\text { Despesas com vendas, gerais e } \\
\text { administrativas }\end{array}$ & $(130,88)$ & $(125,77)$ & $(120,86)$ & $(116,15)$ & $(111,20)$ & $(108,41)$ \\
\hline Outros & $(1,93)$ & $(1,85)$ & $(1,78)$ & $(1,71)$ & $(1,64)$ & $(1,47)$ \\
\hline $\begin{array}{l}\text { Resultado de Equivalência } \\
\text { Patrimonial em Investimentos }\end{array}$ & $(20,93)$ & $(20,11)$ & $(19,32)$ & $(18,57)$ & $(17,78)$ & $(16,65)$ \\
\hline LAJIDA(EBITDA) & $1.658,83$ & $1.814,28$ & $1.863,10$ & $1.904,90$ & $1.958,12$ & $1.268,99$ \\
\hline $\begin{array}{l}\text { Margem EBITDA = EBITDA/ } \\
\text { Receita Líquida }\end{array}$ & $51 \%$ & $58 \%$ & $62 \%$ & $66 \%$ & $71 \%$ & $48 \%$ \\
\hline
\end{tabular}

A tabela 6 apresenta o cálculo do lucro líquido. $\mathrm{O}$ resultado financeiro foi calculado em função do financiamento com o sistema SAC de financiamento. Foi utilizada a premissa de não pagamento de juros sobre o capital próprio (JSCP), mas apenas o pagamento de proventos na forma de dividendos de $25 \%$ sobre o lucro líquido da empresa, o valor determinado pela Lei das SA. Para o cálculo do imposto foi utilizada uma alíquota de $34 \%$ ao ano, sendo $25 \%$ de imposto de renda (IR) e 9\% de Contribuição Social sobre o Lucro Líquido (CSLL). 
Tabela 6 - Lucro Líquido da ALL

\begin{tabular}{|l|r|r|r|r|r|r|}
\hline \multicolumn{1}{|c|}{ Milhões de R\$ } & \multicolumn{1}{c|}{$2014 \mathrm{E}$} & \multicolumn{1}{c|}{$2013 \mathrm{E}$} & \multicolumn{1}{c|}{$2012 \mathrm{E}$} & \multicolumn{1}{c|}{$2011 \mathrm{E}$} & \multicolumn{1}{c|}{$2010 \mathrm{E}$} & \multicolumn{1}{c|}{$2009 \mathrm{E}$} \\
\hline Depreciação e Amortização & $(567,93)$ & $(567,93)$ & $(567,93)$ & $(567,93)$ & $(567,93)$ & $(547,52)$ \\
\hline Lucro Antes de Juros e Impostos LAJIR/EBIT & $1.060,79$ & $1.246,35$ & $1.246,35$ & $1.336,97$ & $1.390,20$ & 721,47 \\
\hline Despesas Financeiras & $(661,49)$ & $(722,32)$ & $(722,32)$ & $(847,79)$ & $(684,32)$ & 0,00 \\
\hline Lucro Antes dos Impostos LAIR & 399,30 & 524,03 & 524,03 & 489,18 & 705,88 & 721,47 \\
\hline Imposto de Renda e CSLL & $(135,76)$ & $(178,17)$ & $(178,17)$ & $(166,32)$ & $(240,00)$ & $(245,30)$ \\
\hline Lucro após impostos & 263,54 & 345,86 & 345,86 & 322,86 & 465,88 & 476,17 \\
\hline
\end{tabular}

Segundo Assaf Neto e Silva (2008), o fluxo de caixa operacional é o fluxo de caixa resultante das operações diárias de uma empresa e é igual ao lucro antes de juros e impostos, acrescido da depreciação (não gera saída monetária), e excluindo o imposto. O fluxo de caixa operacional calculado segundo a equação 7 , é apresentado na tabela 7 .

\section{Equação 7 - Fluxo de Caixa Operacional}

$\mathrm{FCO}=\mathrm{LAJIR}+$ DEPREC.$-(\mathrm{IR}+\mathrm{CSLL})$

Tabela 7 - Fluxo de Caixa Operacional

\begin{tabular}{|l|r|r|r|r|r|r|}
\hline \multicolumn{1}{|c|}{ R\$ Milhões } & \multicolumn{1}{c|}{ 2014E } & \multicolumn{1}{c|}{ 2013E } & \multicolumn{1}{c|}{ 2012E } & \multicolumn{1}{c|}{ 2011E } & \multicolumn{1}{c|}{ 2010E } & \multicolumn{1}{c|}{ 2009E } \\
\hline Lucro Antes de Juros e Impostos LAJIR/EBIT & 737,16 & 767,90 & 763,08 & 751,76 & 736,62 & 721,47 \\
\hline Depreciação & $(567,93)$ & $(567,93)$ & $(567,93)$ & $(567,93)$ & $(567,93)$ & $(547,52)$ \\
\hline Imposto de Renda e CSLL & $(28,82)$ & $(15,50)$ & $(0,47)$ & 0,00 & $(61,62)$ & $(245,30)$ \\
\hline Fluxo de caixa Operacional & $1.276,28$ & $1.320,33$ & $1.330,54$ & $1.319,69$ & $1.242,93$ & $1.023,69$ \\
\hline
\end{tabular}

O CAPEX, apresentado na tabela 8 , designa o montante de dinheiro utilizado na aquisição de bens de capital. Para a variação do CAPEX foi utilizada a variação histórica da empresa a partir de dados de 2007, a partir de dados divulgados pela ALL e feita uma média entre 2007 e 2009.

Tabela 8 - Investimentos de Capital

\begin{tabular}{|l|c|c|c|c|c|c|c|c|}
\hline \multicolumn{1}{|c|}{ R\$ Milhões } & 2014E & 2013E & $2012 \mathrm{E}$ & $2011 \mathrm{E}$ & $2010 \mathrm{E}$ & $2009 \mathrm{E}$ & 2008 & 2007 \\
\hline $\begin{array}{l}\text { Investimentos de Capital } \\
\text { CAPEX }\end{array}$ & $-571,56$ & $-549,25$ & $-525,89$ & $-548,56$ & $-698,79$ & $-592,23$ & $-651,52$ & $-791,67$ \\
\hline
\end{tabular}

Pode-se descontar um fluxo de caixa pelo ponto de vista do capital próprio (equity), ou da empresa inteira que inclui também a dívida. A taxa de desconto utilizada também muda: ao descontar o equity será utilizado o custo de capital próprio $(K e)$ derivado do $C A P M$, já no caso da firma é utilizado o custo médio e ponderado de capital (WACC).
O Fluxo de Caixa dos Ativos representa a variação do fluxo de caixa operacional menos os investimentos e o capital de giro. O capital de giro é o resultado da diferença entre ativos e passivos circulantes. A variação de capital de giro demonstra a variação de capital de giro entre o período observado com o período anterior. 
Tabela 9 - Fluxo de Caixa dos Ativos

\begin{tabular}{|l|r|r|c|c|r|r|}
\hline & \multicolumn{1}{|c|}{$2014 \mathrm{E}$} & \multicolumn{1}{c|}{$2013 \mathrm{E}$} & \multicolumn{1}{c|}{$2012 \mathrm{E}$} & \multicolumn{1}{c|}{$2011 \mathrm{E}$} & \multicolumn{1}{c|}{$2010 \mathrm{E}$} & \multicolumn{1}{c|}{$2009 \mathrm{E}$} \\
\hline Fluxo de caixa Operacional (milhões de R\$) & $1.276,28$ & $1.320,33$ & $1.330,54$ & $1.319,69$ & $1.242,93$ & $1.023,69$ \\
\hline $\begin{array}{l}\text { Investimentos de Capital CAPEX } \\
\text { (milhões de R\$) }\end{array}$ & $(571,56)$ & $(549,25)$ & $(525,89)$ & $(548,56)$ & $(698,79)$ & $(592,23)$ \\
\hline Variação no Capital de Giro Líquido & $(4,88)$ & 6,23 & 28,04 & 40,44 & 51,06 & 85,48 \\
\hline Fluxo de caixa dos Ativos (milhões de R\$) & 699,84 & 777,30 & 832,70 & 811,57 & 595,20 & 516,94 \\
\hline
\end{tabular}

Esse resultado passa a informação da geração de caixa da empresa pago aos acionistas e seus credores.

No caso da ALL, para o calculo da taxa livre de risco foi utilizada a atual taxa SELIC expur- gada de $20 \%$ de imposto de renda, perfazendo $7 \%$ e para o Prêmio de Risco de Mercado, valor de $8,20 \%$, obtida a partir do trabalho de Leal, (2002).

Tabela 10 - Calculo do WACC

\begin{tabular}{|l|r|r|r|r|r|r|}
\hline Custo do Capital Próprio & $14,71 \%$ & $14,71 \%$ & $14,71 \%$ & $14,71 \%$ & $14,71 \%$ & $14,71 \%$ \\
\hline Custo de Capital de Terceiros (Kd) & $12,25 \%$ & $12,25 \%$ & $12,25 \%$ & $12,25 \%$ & $12,25 \%$ & $12,25 \%$ \\
\hline WACC & $9,65 \%$ & $9,66 \%$ & $9,67 \%$ & $9,68 \%$ & $9,69 \%$ & $9,70 \%$ \\
\hline Capital Próprio/ Total Investido & $23,69 \%$ & $23,85 \%$ & $24,00 \%$ & $24,15 \%$ & $24,29 \%$ & $24,41 \%$ \\
\hline
\end{tabular}

Para o cálculo da perpetuidade procedeu-se uma análise de sensibilidade utilizando taxas de crescimento de $-5,0 \%$ até $+5,0 \%$. A data zero utilizada foi o ano de 2009. A Tabela 11 mostra o valor da empresa ao longo dos próximos anos de 2010 até 2014. Para chegar ao valor justo do papel da empresa, de acordo com as premissas impostas ao modelo, é feito então, o somatório dos valores do Fluxo Des- contado, o chamado Enterprise Value. A partir desse valor é subtraiu-se o total da dívida da Empresa. Foi utilizado valor da dívida de 2008 , último completo quando da confecção deste trabalho. O Resultado desta expressão fornece o valor de mercado (Market Cap) da empresa que, dividido pelo número total de papéis listados em bolsa (433.130.218 papéis), resultando no preço da ação.

\section{Tabela 11 - Valor Justo do Ativo pela Variação do Crescimento}

\begin{tabular}{|r|r|r|r|r|}
\hline $\begin{array}{c}\text { Taxa de } \\
\text { Crescimento }\end{array}$ & $\begin{array}{c}\text { Fluxo de Caixa } \\
\text { Descontado }\end{array}$ & Dívida (R\$ MM) & $\begin{array}{c}\text { Valor de Mercado } \\
\text { (R\$MM) }\end{array}$ & Valor da Ação \\
\hline $5 \%$ & $17.772,14$ & 2495,5 & $15.276,64$ & $\mathrm{R} \$ 35,27$ \\
\hline $4 \%$ & $15.109,58$ & 2495,5 & $12.614,08$ & $\mathrm{R} \$ 29,12$ \\
\hline $3 \%$ & $13.247,79$ & 2495,5 & $10.752,29$ & $\mathrm{R} \$ 24,82$ \\
\hline $2 \%$ & $11.872,74$ & 2495,5 & $9.377,24$ & $\mathrm{R} \$ 21,65$ \\
\hline $1 \%$ & $10.815,63$ & 2495,5 & $8.320,13$ & $\mathrm{R} \$ 19,21$ \\
\hline $0 \%$ & $9.977,60$ & 2495,5 & $7.482,10$ & $\mathrm{R} \$ 17,27$ \\
\hline$-1 \%$ & $9.296,95$ & 2495,5 & $6.801,45$ & $\mathrm{R} \$ 15,70$ \\
\hline$-2 \%$ & $8.733,15$ & 2495,5 & $6.237,65$ & $\mathrm{R} \$ 14,40$ \\
\hline$-3 \%$ & $8.258,49$ & 2495,5 & $5.762,99$ & $\mathrm{R} \$ 13,31$ \\
\hline$-4 \%$ & $7.853,37$ & 2495,5 & $5.357,87$ & $\mathrm{R} \$ 12,37$ \\
\hline$-5 \%$ & $7.503,56$ & 2495,5 & $5.008,06$ & $\mathrm{R} \$ 11,56$ \\
\hline
\end{tabular}


O preço da ação da ALL varia de R $\$ 11,56$ (taxa de perpetuidade de -5,0\%) para $\mathrm{R} \$ 35,27$ (taxa de perpetuidade de $+5,0 \%$ ). A seguir, será feita a avaliação da ALL por múltiplo de Ebitda.

\subsubsection{Avaliação por Múltiplo de Ebitda}

$\mathrm{Na}$ avaliação relativa são comparados os múltiplos de uma determinada empresa com os de outras empresas similares que, preferencialmente, atuem no mesmo setor para que se possa chegar ao preço da empresa. Será verificada a média dos múltiplos das empresas comparáveis ou do setor onde aquela se encontra e, dessa forma, calcular o preço justo para o ativo e sua expectativa de valorização. Neste trabalho utilizou-se o Valor da firma / EBITDA (Enterprise value / EBITDA).

A America Latina Logística não possui empresas semelhantes de capital aberto no Brasil, restando compará-la a seus pares internacionais. As empresas estrangeiras escolhidas para serem utilizadas na determinação dos múltiplos comparáveis à ALL são a Burlington Northern Santa Fé Corp., a Union Pacific Railroad, a CSX Transportation Inc., Norfolk Southern Railway Company e a Kansas City Southern Railway, todas empresas americanas pertencentes ao grupo denominado "Class I Railroads". A chamada ferrovia de classe I reúne as companhias ferroviárias de grande porte e que possuem receita operacional anual acima de US\$ 250 milhões após terem sua margem de lucro corrigida pelo índice ferroviário.

A Burlington Northern Santa Fé Corp. opera o maior sistema ferroviário da América do Norte. A BNFS opera um sistema de 32.000 milhas de extensão que atravessam vinte e oito estados e duas províncias canadenses. Cerca de 8.000 milhas são concessões.

A Union Pacific Railroad (UP) é o segmento operacional da Union Pacific Corporation, e esta ferrovia abrange vinte e três estados. A UP é a maior e mais antiga rede ferroviária em operação nos EUA e possui aproximadamente 33.000 milhas, que ligam a Costa do Pacífico e a Costa do Golfo com os portos do centro oeste e do leste.

A CSX Corporation possui empresas com operações ferroviárias e intermodais de logística interligando trem e caminhões, abrangendo mais de 70 rios, oceanos e lagos, e mais de 200 ferrovias de curta distância. A principal empresa operacional, CSX Transportation Inc., possui $22.000 \mathrm{mi}-$ lhas atravessando vinte e três estados, o distrito de Columbia e duas províncias canadenses.
A Norfolk Southern Corporation é a controladora da Norfolk Southern Railway Company (NS). A ferrovia opera 21.300 milhas em vinte dois estados, os distritos de Columbia e Ontário, interligando todos os portos do leste com algumas ferrovias do oeste e do Canadá. A NS também oferece uma extensa rede intermodal no leste da América do Norte.

A Kansas City Southern é a menor ferrovia de Classe I. Possui e opera cerca de 3.100 milhas de ferrovias no meio oeste e no sudoeste dos Estados Unidos. A KCS oferece serviços de frete no México, através da subsidiária Kansas City Southern de México (KCSM), uma das principais ferrovias mexicanas. Opera os três maiores portos no México, e 15 estados mexicanos e a cidade do México. A KCS também controla a Texas Mexican Railway, que faz a conexão entre os sistemas da KCSR e da KCSM.

A ALL possui algumas diferenças em relação às empresas norte americanas, como possuir um sistema de logística integrado, ao contrário das outras ferrovias, com exceção da CSX. No seu mercado de atuação, a ALL é concessionária do serviço de transporte, enquanto as empresas americanas possuem suas próprias ferrovias. A ALL atua exclusivamente em sua área de cobertura, ao contrário das empresas americanas que disputam por muitas vezes a mesma área.

O cálculo dos múltiplos escolhidos para a avaliação relativa será baseado no histórico a partir de 2005 e na projeção para os resultados de 2009 das empresas selecionadas. Analisando o múltiplo de EV/EBITDA (Valor da Firma / Ebitda) pela tabela 12 observa-se sua variação para as empresas americanas entre 8,3 e 10,0. Utilizando a média destes valores e aplicando aos valores projetados de EBITDA e dívida líquida da ALL para o ano de 2009 encontram-se valores por ação que variam de 18,34 até 23,41 com média em 19,84. Este indicador mede o preço de uma empresa que o investidor paga em benefício do fluxo de caixa desta sob a forma do EBITDA. O EV/EBITDA tem a vantagem de não ser afetado pela estrutura de capital da empresa, sendo que o valor da firma subtrai o valor de suas dívidas do valor de mercado da empresa, e o EBITDA exclui o pagamento de juros sobre essa dívida. Uma das desvantagens é que este indicador somente deve ser utilizado para empresas intensivas em capital, sendo que este fato não afeta o presente estudo. 
Tabela 12 - EV/EBITDA para Empresas Norte Americanas

\begin{tabular}{|l|r|r|r|r|r|r|}
\hline & $200912 \mathrm{~m}$ & $20091 \mathrm{~T}$ & 2008 & 2007 & 2006 & 2005 \\
\hline BNI & 8,3 & 6,6 & 7,7 & 7,8 & 7,5 & 6,9 \\
\hline CSX & 8,3 & 6 & 8,1 & 7,6 & 6,4 & 6,8 \\
\hline KSU & 10 & 7,1 & 10,1 & 8,3 & 7,7 & 9,1 \\
\hline NSC & 8,9 & 5,8 & 7 & 7,5 & 7,6 & 7,4 \\
\hline UNP & 8,4 & 6 & 7,6 & 7,8 & 7,3 & 5,3 \\
\hline média & 8,8 & 6,3 & 8,1 & 7,8 & 7,3 & 7,1 \\
\hline mediana & 8,4 & 6 & 7,7 & 7,8 & 7,5 & 6,9 \\
\hline desvio padrão & 0,7 & 0,6 & 1,2 & 0,3 & 0,5 & 1,4 \\
\hline mínimo & 8,3 & 5,8 & 7 & 7,5 & 6,4 & 5,3 \\
\hline máximo & 10 & 7,1 & 10,1 & 8,3 & 7,7 & 9,1 \\
\hline
\end{tabular}

Fonte: www.sec.gov

É possível verificar que os valores encontrados pelas avaliações estão de acordo com a média de consenso entre analistas de mercado (target) de $\mathrm{R} \$ 18,30$. Essa é uma média das projeções feitas no período entre abril e junho de 2010 por diversas corretoras de valores brasileiras. Essas variações são motivadas pelas premissas utilizadas por cada banco ou corretora e não dizem se esta é correta ou errada, apenas que cada reflete o sentimento do analista naquele instante. $\mathrm{O}$ resultado se encontra próximo ao resultado do fluxo de caixa descontado para taxa de crescimento perpétuo nula $(\mathrm{R} \$ 17,27)$. Isso sugere uma convergência de resultados entre os dois métodos utilizados, conferindo consistência à avaliação.

\section{CONCLUSÃO}

A intenção principal deste projeto foi aplicar dois dos métodos de precificação de empresas mais utilizados atualmente. De fato, o Instituto Brasileiro de Economia da Fundação Getúlio Vargas (IBRE/FGV), dedicado à produção e divulgação de estatísticas e pesquisas econômicas aplicadas, em trabalho realizado em 2005 com analistas de mercado e investidores individuais brasileiros, e apresentada no jornal Valor Econômico de $24 / 08 / 2005$, concluiu que o fluxo de caixa descontado foi escolhido por $89,77 \%$ dos entrevistados, seguido pelo valor da empresa sobre o seu EBTIDA com 79,55\% das escolhas.

Como forma de exemplificar a aplicação dos métodos, foi utilizada a empresa América Latina Logística (ALL) que atua no setor de transporte ferroviário com concessões em algumas áreas brasileiras e também na Argentina. A ALL é líder neste setor no Brasil e um dos principais players na América Latina.

Os resultados similares encontrados nos dois métodos conferem consistência à avaliação da ALL, sugerindo que os dois modelos de valuation podem conviver sem grandes distorçóes no setor estudado.

A avaliação da empresa pelo EBITDA se torna incompleta em relação ao fluxo de caixa dos ativos (FCA) pelo fato desse levar em consideração além do EBITDA, os investimentos em capital, tirando a depreciação, e as alterações de capital de giro líquido. Esses elementos e os fatores que os afetam demandam uma previsão mais cuidadosa pela sua importância na avaliação pelo fluxo de caixa descontado. Isso confere maior consistência à avaliação pelo fluxo de caixa descontado na precificação de uma empresa. Além disso considera, entre outros fatores, a estrutura e o custo das fontes de capital, os riscos para os acionistas e credores e os benefícios fiscais.

A convergência dos valores confere consistência ao resultado e denota que, para a empresa estudada, a distorção que frequentemente ocorre com o método de múltiplos de EBITDA foi menos acentuada.

Uma sugestão para futuros trabalhos é a comparação entre os dois métodos utilizados em um setor menos intensivo em capital, como, por exemplo, o varejo. Eventuais divergências encontradas podem dar subsídios para a escolha do método de avaliação de empresas. 


\section{REFERÊNCIAS BIBLIOGRÁFICAS}

ASSAF NETO, Alexandre. Mercado financeiro. 8. ed. - 2. reimpr. São Paulo: Atlas, 2008.

CAVALCANTE, Francisco; MISUMI, Jorge Yoshio; RUDGE, Luiz Fernando. Mercado de Capitais o que é, como funciona. 6 .rd - 2 reimpr. Rio de Janeiro: Elsevier, 2005.

COPELAND, Tom; KOLLER, Tim; MURRIN, Jack. Avaliação de empresas - Valuation: Calculando e gerenciando o valor das empresas. 3. ed. São Paulo: Makron Books Ltda., 2002.

DAMODARAN, Aswath. Avaliação de empresas.

2. ed. São Paulo: Pearson Prentice Hall, 2007.

Avaliação de Investimentos: ferramentas e técnicas para a determinação do valor de qualquer ativo. 1. ed.- 5 reimpr. Rio de Janeiro, Qualitymark Editora, 2003

FLEURY, Paulo Fernando ; WANKE, Peter; FIGUEREIDO, Kleber Fossati. Logística Empresarial: a perspectiva brasileira. 1 ed- 11 reimpr. São Paulo, Atlas. 2009

GRAHAM, J.R. and HARVEY, C.R. (2001), "How do CFOs make capital budgeting and capital structure decisions?", The Journal of Applied Corporate Finance Vol. 15, No. 1, 2002

LIMA, Iran Siqueira; GALARDI, Ney; NEUBAUER, Ingrid. Mercados de investimentos financeiros. 2. ed. São Paulo: Atlas, 2008.

PÓVOA, Alexandre. Valuation Como Precificar ações. 1 ed. São Paulo. Editora Globo, 2004

BORDEAUX-RÊGO, Ricardo; PAULO, Goret Pereira; SPRITZER, Ilda Maria de P. A.; ZOTES, Luis Peres. Viabilidade econômico-financeira de projetos. 2a . ed. Rio de Janeiro: Editora FGV, 2009.
RELATORIO FOCUS-BCB 2009

ROSS, Stephen A.; WESTERFIELD, Randolph W.; JORDAN, Bradford D.. Princípios de administração financeira. 2. ed. - 7. reimpr. São Paulo: Atlas, 2008.

SILVA, Luiz Walter Migueis. Métodos de avaliação de empresas: casos de práticas adotadas no Brasil. Dissertação de Mestrado - Faculdades Ibmec. Rio de Janeiro, 2006.

FLEURY, Paulo Fernando, WANKE, Peter, FIGUEIREDO, Kleber Fossati, Logística Empresarial: A Perspectiva Brasileira. 1.ed - 1.reimpr. Rio de Janeiro, 2000.

LEAL, Ricardo. P. Revisão da literatura sobre estimativa do custo de capital aplicada ao Brasil, Coppead, UFRJ, mimeo, 2002.

Governance practices and corporate value: a recent literature survey. Revista de Administração de Empresas da USP - RAUSP, v. 39, n.4, p. 327-337, 2004.

TOBIN, J. e BRAINARD, W. Pitfalls in Financial Model Building, American Economic Review, v.58, n.2, May, 1968.

TOBIN,J. A General /equilibrium Approach to Monetary Theory, Journal of money, Credit and Banking, v. 1, n.1, Feb. 1969.

WWW.ALL-LOGISTICA.COM.BR

WWW.ANP.GOV.BR

WWW.ANTT.GOV.BR

WWW.BOVESPA.COM.BR

WWW.BLOOMBERG.COM

WWW.CVM.COM.BR 